CRYSTAL AND ELECTRONIC STRUCTURE OF AQUA(NSALICYLIDENE-METHYLESTER-L-GLUTAMATO)Cu(II) MONOHYDRATE

V. Langer, ${ }^{1}$ D. Gyepesova, ${ }^{2}$ E. Scholtzova, ${ }^{2}$ M. Kohutova, ${ }^{3}$ A. Valent ${ }^{3}$

${ }^{1}$ Chalmers University of Technology Inst. of Env. Inorg. Chemistry SE-412 96 Gothenburg SE-412 96 Sweden ${ }^{2}$ Inst. of Inorg. Chemistry, Slovak Acad. of Sci., SK-842 36 Bratislava, Slovak Rep. ${ }^{3}$ Faculty of Pharmacy, Comenius Univ., SK-832 32 Bratislava, Slovak Rep.

The crystal structure of aqua(N-salicylidene-methylester-Lglutamato)copper(II) monohydrate has been determined. The structure was refined by SHELXL-97 to $\mathrm{R}=0.0344$ for 5318 unique reflections taken at the temperature $183 \mathrm{~K}, 229$ parameters being refined. The crystal structure consists of the molecular units $\left[\mathrm{Cu}(\mathrm{N}-\mathrm{sal}-5-\right.$ met-L-glu $\left.)\left(\mathrm{H}_{2} \mathrm{O}\right)\right]$ connected by three dimensional network of hydrogen bonds. The coordination polyhedron in the complex is approximately square-pyramidal with the pentacoordinated $\mathrm{Cu}$ (II) atom. The base of the pyramid is formed by the phenolic O3, carboxylic $\mathrm{O} 5$ and azometine $\mathrm{N} 1$ atoms of the Schiff-base anion and by $\mathrm{O} 4$ atom of the water molecule. The apex of the pyramid contains weakly bonded O6 atom of the carboxylic group of another molecule. The base of the pyramide bond distances are 1.9267(14), 1.9492(14), 1.9312(16) and 1.9715(14) ^, respectively. The apical bond length is $2.3929(15) \AA$. The quantum chemical calculations of the electron structure were done by Gaussian98 program package using B3LYP/SVP method and basis set. The calculation of Mulliken population analysis, and contributions of individual atomic orbitals to $\mathrm{Cu}-\mathrm{O}$

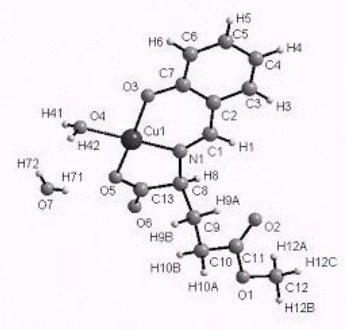
and $\mathrm{Cu}-\mathrm{N}$ bonds were done for doublet as the most stable multiplet state. Calculated bond populations indicated that while the bonds $\mathrm{Cu} 1$ to $\mathrm{O} 3, \mathrm{~N} 1$ and $\mathrm{O} 5$ are almost equivalent $(0.211,0.228,0.201|\mathrm{e}|$, respectively), the $\mathrm{Cu} 1$ $\mathrm{O} 4$ bond is significantly weaker $(0.137|\mathrm{e}|)$. Synthesis and structure determination of title compound was stimulated due to found antimicrobial activities of $\mathrm{Cu}(\mathrm{II})$ complexes containing Schiff - bases derived from salicylaldehyde and L-glutamic acid as well as its methyl and ethylesters.

Keywords: Cu/II/ COMPLEX SCHIFF BASE B3LYP

Acta Cryst. (2002). A58 (Supplement), C133

STRUCTURE AND BIOLOGICAL ACTIVITY OF Zn(II) COMPLEX WITH TRIS(BENZIMIDAZOL-2-YLMETHYL)AMINE(NTB) LIGAND X. L. Liu ${ }^{1}$ R. Zhao ${ }^{2}$ X. Wen ${ }^{3}$ F. M. Miao ${ }^{4}$

${ }^{1}$ Tianjin Normal University College of Chemistry And Life Science College of Chemistry and Life Science, Tianjin Normal University, 300074 Tianjin TIANJIN 300074 CHINA ${ }^{2}$ The Naval Logistics Institute, Tianjin Tanggu, $300400{ }^{3}$ Department of Chemical Engineering, Tianjin Institute of Technology, 300191 Tianjin, P. R. China ${ }^{4}$ College of Chemistry and Life Science, Tianjin Normal University, 300074 Tianjin, P. R. China

Since the structures of superoxide dismutase (SOD) exhibit that most of the coordinated atoms around metal ions are from imidazole groups of histidines which are the primary ligands in distorted coordination geometry [1-2] , an important step should be to design to synthetic models of SOD in which ligands should contain imidazole groups. In order to elucidate the properties of SOD model compounds, a new Zn (II) mononuclear complex with NTB was synthesized with stoichiometry of $\mathrm{ZnNTB} 2\left(\mathrm{NO}_{3}\right)$ dipy dmf (dipy: 4,4dipyridyl). The complex was characterized with element analysis, UV and IR spectra. The crystal structure was determined using X-ray diffraction method. A total of 7975 reflections were collected on a Brucker AXS Smart-1000 CCD diffractometer. 4844 observed reflections were used in the structure analysis and refinements with 514 variables. The structure was solved by direct and fourier synthesis method. The crystallographic parameters are as follows :

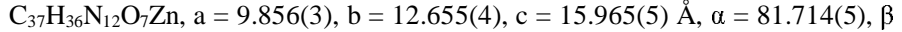
$=76.601(5), \gamma=81.504(5)^{\circ}, \mathrm{Z}=2, \mathrm{~F}(000)=856$, space group $P-1, \mathrm{R}=0.0424$, $\mathrm{wR}=0.0936, \mathrm{~S}=1.013$. The crystal structure indicates that four $\mathrm{N}$ atoms and one $\mathrm{O}$ atom coordinate to $\mathrm{Zn}$ (II) ion to construct a distorted triganal-bipyramid configuration. The activity assay shows that this complex with Bipy presents certain biological activity.

References

1. Tainer, J. A., Getzoff, E. D., Beem, K. M., Richardson, J. S. and Richardson, D. C., J. Mol. Biol., 1982, 160, 181.

2. Rypniewski, W. R., Mangani, S., Bruni, B., Orioli, P. L., Casati, M. and Wilson, K. S., J. Mol. Biol., 1995, 251, 282.

Keywords: Zn(II) COMPLEX CRYSTAL STRUCTURE BIOLOGICAL ACTIVITY
Acta Cryst. (2002). A58 (Supplement), C133

\section{STRUCTURAL DIVERSITY OF COPPER(II) CARBOXYLATES WITH 4-AMINOPYRIDINE}

I. Leban N. Lah P. Segedin

University of Ljubljana Faculty of Chemistry and Chemical Technology Askerceva 9 LJUBLJANA SI-1231 SLOVENIA

Reactions of copper(II) carboxylates with 4-aminopyridine (4-apy) were investigated and their products structurally characterized by single crystal Xray diffraction. Reaction of $\mathrm{Cu}$ (II) acetate resulted in two isomers of the composition $\mathrm{Cu}$ (acetate $)_{2}(4 \text {-apy })_{2}$ with markedly different stability: the violet form - unstable in air and the blue - stable form. In both isomers the ligands are arranged around the copper atom in a trans mode. The 4-apy ligands lie almost in the plane in the violet form, while they are twisted with respect to each other in the blue form. Variations were observed also in the coordination of the acetate groups to the copper ion

Monomeric complexes of the same stoichiometry were obtained also by the reaction of $\mathrm{Cu}$ (II) hexanoate (hex) and heptanoate (hep) with 4-apy. The violet $\mathrm{Cu}(\text { hex })_{2}(4 \text {-apy })_{2}$, and $\mathrm{Cu}$ (hep $)_{2}$ (4-apy $)_{2}$, are isostructural and possess trans geometry of the ligands around the copper centre.

Reaction of 4-apy with $\mathrm{Cu}$ (II) octanoate lead to a formation of a novel, unprecedented basic centrosymmetric tetranuclear compound of composition $\mathrm{Cu} 4(\mathrm{oct})_{6}(\mathrm{OH})_{2}(4 \text {-apy })_{2}$. Molecule contains bidentate bridging and monoatomic bridging carboxylate groups, triply bridging hydroxyl groups and 4-aminopyridine as a terminal ligand. In all five compounds 4-apy is coordinated through endocyclic nitrogen atom only.

\section{Keywords: COPPER(II) COMPLEXES CARBOXYLATES AMINOPYRIDINE}

\section{Acta Cryst. (2002). A58 (Supplement), C133}

\section{THE X-RAY INVESTIGATION OF CO(III) DIOXIMATE COMPLEXES WITH BF ${ }_{4}^{-}$OR $\mathrm{CF}_{3} \mathrm{SO}_{3}^{-}$ANIONS}

$\underline{\text { St. Malinovski }}^{1,4}$ E. Coropceanu ${ }^{1}$ M. Gdanec ${ }^{2}$ K. Suwinska ${ }^{3}$ R. Luboradzki ${ }^{3}$ O. Bologa ${ }^{1}$ H. Stoeckli - Evans ${ }^{4}$

Universite De Neuchatel (On Leave Moldavian Academy of Sc.) Institut De Chimie, Chemical Crystallography Avenue De Bellevaux 51 Case Postal 2 NEUCHATEL NEUCHATEL CH - 2007 SWITZERLAND

${ }^{1}$ Institute of Chemistry, Moldavian Academy of Scienses, R.Moldova, Kishinev ${ }^{2}$ Faculte of Chemistry, A. Mickiewicz University, Poznan, Poland ${ }^{3}$ Institute of Physical Chemistry, Polish Academy of Sciences, Warshawa, Poland ${ }^{4}$ Institute of Chemistry of Neuchatel University, Neuchatel, Switzerland

An investigation of $\mathrm{Co}$ (III) dioximate complexes, has shown that the reaction conditions play a determining role on their composition, structure and biological properties. X-ray analysis of five new $\mathrm{Co}(\mathrm{III})$ dioximates, with tetrafluoroborate and triflate anions, $\left[\mathrm{Co}(\mathrm{DH})_{2} \quad\left(\mathrm{NH}_{3}\right)_{2}\right] \mathrm{BF}_{4}, \quad\left[\mathrm{Co}(\mathrm{MH})_{2}\right.$ (Thio $\left.)_{2}\right] \mathrm{BF}_{4},\left[\mathrm{Co}(\mathrm{NioxH})_{2}(\mathrm{Py})_{2}\right] 2\left[_{4}\right]_{2},\left[\mathrm{Co}(\mathrm{DH})_{2}(\mathrm{Thio})_{2}\right] \mathrm{CF}_{3} \mathrm{SO}_{3}$ and $\left[\mathrm{Co}(\mathrm{DH})_{2}\right.$ $(\mathrm{Py})_{2} \mathrm{CF}_{3} \mathrm{SO}_{3}$, iindicates that the metal has a normal octahedral environment. The 4-N equatorial plane (eq), formed by two residues of (DH), (MH) and (NioxH) ( $\mathrm{DH}_{2}$ dimethylglioxyme, $\mathrm{MH}_{2}$ methylglioxyme and $\mathrm{NioxH}_{2}$ nioxyme), are coplanar within $1.2-1.6^{\circ}$. The mean $\mathrm{Co}-\mathrm{N}_{\mathrm{eq}}$ distance is $1.886 \AA$. The apical positions of the polyhedron are occupied by the nitrogen and sulphur atoms of the $\mathrm{NH}_{3}$, Thio or Py ligands. The mean Co-N $\left(\mathrm{NH}_{3}\right)$, Co-S(Thio) and Co-N(Py) distances are 1.964, 2.281 and $1.963 \AA$, respectively. The $\mathrm{DH}$ ligands are linked by two $\mathrm{O}-\mathrm{H}$... O intramolecular hydrogen bonds, mean $\mathrm{O} \ldots \mathrm{O}$ distance of $2.52 \AA$. The nature of the equatorially coordinated ligand, or the different neutral ligands in the trans positions, does not change the configuration of the complex cation. Biological tests indicate that the tetrafluoroborate complexes have a much stronger influence on the enzymatic activity of the genera Aspergillus niger 33, as an amylase producer, compared to the triflate complex.

\section{Keywords: COMPLEX, ANION, HYDROGEN BOND}

